
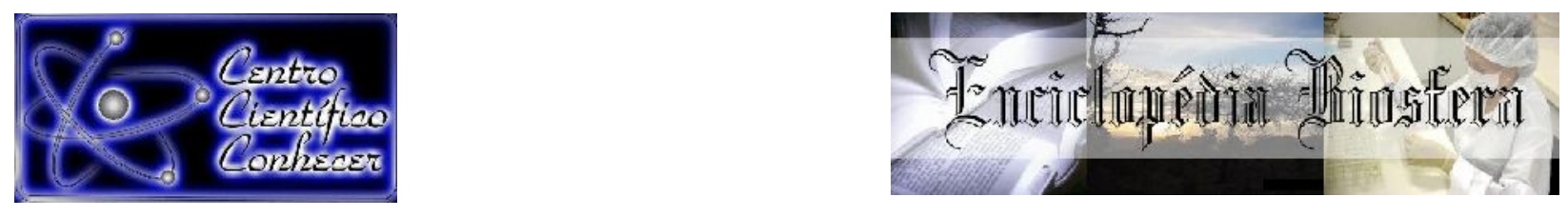

\title{
POTENCIAL ANTIPROLIFERATIVO DE EXTRATOS AQUOSOS DE CASCAS DE Handroanthus chrysotrichus (Mart. ex DC.) Mattos PELO TESTE Allium Cepa L.
}

Julia de Senna Pereira1, Luísa Gonçalves Rodrigues², Jéssica Mena Barreto de Freitas $^{3}$, Solange Bosio Tedesco ${ }^{4}$

1 Mestranda em Agrobiologia na Universidade Federal de Santa Maria (juliadesennapereira@gmail.com).Santa Maria- Brasil

2 Mestranda em Agrobiologia na Universidade Federal de Santa Maria

3 Mestre em Agrobiologia pela Universidade Federal de Santa Maria

4 Professora Doutora do Departamento de Biologia da Universidade Federal de Santa Maria

Recebido em: 06/04/2019 - Aprovado em: 10/06/2019 - Publicado em: 30/06/2019 DOI: 10.18677/EnciBio_2019A149

\begin{abstract}
RESUMO
A espécie Handroanthus chrysotrichus (Mart. ex DC.) Mattos, popularmente conhecida como ipê-amarelo, possui propriedades adstringentes, sendo utilizadas pela população para tratar infecções bucais, prevenir ataques cardíacos e aumento da imunidade. O objetivo desse estudo foi avaliar o potencial genotóxico e antiproliferativo de extratos aquosos de ipê-amarelo pelo teste in vivo de Allium cepa L., sendo os extratos preparados a partir das cascas de um indivíduo dessa espécie coletado em Santa Maria, RS. As decocções das cascas foram preparadas em três concentrações: $5 \mathrm{gL}$ 1, $10 \mathrm{gL}{ }^{1}$ e $15 \mathrm{gL}$ 1, e água e glifosato 1,5\% como controles negativo e positivo, respectivamente. Foram utilizados cinco grupos de quatro bulbos de cebola, onde cada grupo correspondia a um tratamento. Os bulbos de cebola foram enraizados em água destilada por 72 horas. Após esse período, as radículas foram coletadas, fixadas em etanol:ácido acético (3:1) por 24 horas e armazenadas em álcool $70 \%$ sob refrigeração. Foram analisadas 4000 células por grupo de bulbos, os resultados foram submetidos à análise da variância (ANOVA) e os valores dos índices mitóticos foram comparados pelo teste de Tukey com 5\% de probabilidade de erro, com o auxílio do programa Sisvar 5.6. Os resultados indicaram que houve redução dos índices mitóticos em todos os tratamentos quando comparados com o controle negativo em água. Conclui-se que os extratos aquosos de ipê-amarelo nas concentrações estudadas possuem ação antiproliferativa e não genotóxica sobre o ciclo celular de Allium cepa.
\end{abstract}

PALAVRAS-CHAVE: atividade antiproliferativa; allium cepa, ipê-amarelo

\section{ANTIPROLIFERATIVE ANALYSIS OF AQUEOUS EXTRACTS OF Handroanthus chrysotrichus (Mart. ex DC.) Mattos ON THE CELL CYCLE OF Allium cepa L}

\section{ABSTRACT}

The species Handroanthus chrysotrichus, popularly known as, has astringent properties, being used by the population to treat mouth infections, prevent heart attacks and increase immunity. The objective of this study was to evaluate the 
genotoxic and antiproliferative potential of ipê-amarelo aqueous extracts by the in vivo test of Allium cepa, the extracts being prepared from the barks of an individual of this species collected in Santa Maria, RS. The bark decoctions were prepared in three concentrations: $5 \mathrm{gL}{ }^{1}, 10 \mathrm{gL}$, and $15 \mathrm{gL}{ }^{1}$, and water and glyphosate $1.5 \%$ as negative and positive controls, respectively. Five groups of four onion bulbs were used, each corresponding to one treatment. The onion bulbs were rooted in distilled water for 72 hours. After this period, the radicles were collected, fixed in ethanol: acetic acid (3:1) for 24 hours and stored in $70 \%$ alcohol under refrigeration. The amountof 4000 cells per bulb group were analyzed, the results were submitted to analysis of variance (ANOVA) and mitotic index values were compared by Tukey test with $5 \%$ of error probability, with the aid of the Sisvar 5.6 program. The results indicated that mitotic indexes were reduced in all treatments when compared to the negative control in water. It is concluded that the aqueous extracts of ipê-amarelo in the studied concentrations have antiproliferative and non-genotoxic action on the cell cycle of Allium cepa.

KEYWORDS: antiproliferative activity; ipê-amarelo; Allium cepa.

\section{INTRODUÇÃO}

O uso de plantas medicinais como método de prevenção, cura e tratamento de doenças é uma das maneiras mais antigas de prática medicinal utilizada pela humanidade, principalmente através de chás (VEIGA JUNIOR et al., 2005). Esses chás, na grande maioria, são utilizados como tratamento alternativo para várias doenças por pessoas que não possuem acesso aos tratamentos convencionais, sendo que, os tratamentos alternativos são basicamente derivados de produtos naturais a base de plantas na forma natural ou porções de plantas. Entretanto, a utilização inadequada e não controlada pode causar mais danos do que benefícios para a saúde humana devido à capacidade tóxica destas plantas (LEAL; TELLIS, 2015; MELO et al., 2017; NÓBREGA et al., 2017).

A família Bignoniaceae possui cerca de 110 gêneros e 800 espécies distribuídas em regiões tropicais e subtropicais, sendo amplamente presente na América do Sul (LEITE et al., 2017). Originalmente, todas as espécies conhecidas como ipês eram incluídas no gênero Tabebuia, o qual foi criado por De Candolle (1838) para abrigar as Bignoniáceas arbóreas de folhas simples. Entretanto, mais recentemente, Grose e Olmstead (2007) propuseram, com base em estudos filogenéticos, a divisão das espécies de ipês em três gêneros: Tabebuia, Handroanthus (especialmente criado por Mattos em 1907 para os representantes brasileiros) e Roseodendron, confirmando, em definitivo, a segregação proposta por Mattos (1970) e a existência de linhagens diferentes dentro do grupo (SANTOS, 2017).

O gênero Handroanthus é representado por 24 espécies, sendo a maioria arbórea, estando presentes na Amazônia, Caatinga, Cerrado, Mata Atlântica e Pantanal, conhecidas popularmente como ipê ou pau-d'arco (LEITE et al., 2017). A espécie Handroanthus chrysotrichus (Mart. ex DC) Mattos é popularmente conhecida como ipê-amarelo, possui porte médio e é comumente utilizada para arborização urbana e reflorestamento (PEREIRA et al., 2015). O ipê-amarelo ainda possui uso medicinal (LUNELLI et al., 2016), as cascas, quando cozidas, possuem propriedades adstringentes, sendo utilizadas em gargarejos para infecções bucais (PLANTAS, 2019). Também tem sido empregada para aumento da imunidade, 
controle de pressão alta e diminuição do risco de ataque cardíaco (BOLSON et al., 2015).

Inúmeras plantas que são usadas como fitoterápicos necessitam de um maior controle de qualidade, Ferreira et al., (2016) relataram que os produtos derivados de plantas medicinais podem conter substâncias tóxicas com efeitos mutagênicos, sendo necessários ainda mais estudos sobre os efeitos dos usos destas ervas (PLANTAS MEDICINAIS, 2019). Com isso, a utilização de ensaios biológicos para o monitoramento da atividade de extratos, frações e compostos químicos isolados tem sido frequentemente incorporada à identificação e monitoramento de substâncias potencialmente tóxicas (NOLDIN et al., 2003).

O teste Allium cepa L. é um ensaio biológico amplamente utilizado para determinar o potencial genotóxico, mutagênico, citogenético e antiproliferativo de extratos de plantas sendo utilizado como excelente bioindicador vegetal (TEDESCO; LAUGHINGHOUSE, 2012). Este teste está validado pela Organização Mundial da Saúde (OMS) e estudos demonstram que existe correlação positiva do teste de $A$. cepa com outros tipos celulares, bem como células animais (HERRERO et al., 2012).

Além da grande utilização nos testes de citotoxicidade/mutagenicidade de plantas medicinais, o sistema teste de $A$. cepa pode ser utilizado para 0 monitoramento da poluição ambiental e avaliação do potencial mutagênico de muitos compostos químicos (BAGATINI et al., 2007). O método de avaliação, sistema $A$. cepa, é validado pelo Programa Internacional de Segurança Química (PISQ, OMS) e pelo Programa Ambiental das Nações Unidas (PANU) como um teste eficaz para análise e monitoramento in situ da genotoxicidade de substâncias ambientais. Neste contexto, o presente trabalho teve como objetivo avaliar o potencial genotóxico e antiproliferativo de extratos aquosos das cascas de Handroanthus chrysotrichus pelo teste in vivo de Allium cepa.

\section{Coleta}

\section{MATERIAL E MÉTODOS}

Foram coletadas cascas do caule de Handroanthus chrysotrichus (ipê amarelo) no Campus Sede da Universidade Federal de Santa Maria (UFSM), com coordenadas 2942'55.7"S e 5343'05.5”W em Camobi, Rio Grande do Sul, Brasil. As cascas foram lavadas em água corrente para a retirada de musgos e liquens.

\section{Preparo dos extratos}

As cascas de $H$. chrysotrichus foram pesadas em balança de precisão e em seguida foram preparados os extratos pela técnica de decocção por 10 minutos, as concentrações utilizadas foram de $5 \mathrm{gL}{ }^{1}, 10 \mathrm{gL}{ }^{1} \mathrm{e} 15 \mathrm{gL}{ }^{1}$. Após, os extratos aquosos foram filtrados e resfriados à temperatura ambiente.

\section{Teste Allium cepa}

Foram utilizados cinco grupos de quatro bulbos de Allium cepa, cada grupo correspondendo a um dos tratamentos. Os cinco grupos foram colocados para enraizar em água destilada e após a emergência das raízes, cada grupo foi transferido para o seu respectivo tratamento. O primeiro grupo foi usado como controle negativo, mantendo-se em água destilada e o restante, respectivamente, foi transferido para os seguintes tratamentos: glifosato 1,5\% (controle positivo), chá de $5 \mathrm{gL}{ }^{1}$, chá de $10 \mathrm{gL}^{1}$ e chá de $15 \mathrm{gL}{ }^{1}$, e permaneceram por 24 horas. Após este período, as radículas foram coletadas e fixadas em etanol:ácido acético (3:1) 
durante 24 horas. Posteriormente, as raízes foram mantidas em álcool $70 \%$ e conservadas sob refrigeração até o preparo das lâminas.

\section{Confecção e análise das lâminas}

Para análise e contagem das células foram feitas duas lâminas por bulbo e contadas 500 células por lâmina. O preparo das lâminas foi realizado pela técnica de esmagamento (GUERRA; SOUZA, 2002), eas raízes passaram por hidrólise em $\mathrm{HCL} 1 \mathrm{~N}$ por cinco minutos em temperatura ambiente, em seguida lavadas em água destilada e tiveram a região meristemática retirada e então corada com orceína acética $2 \%$. Essa região meristemática foi esmagada com um bastão de vidro e sobre este material foi colocado uma lamínula. Com auxílio de microscopia óptica em aumento de 40X foram analisadas 500 células por lâmina, levando em consideração as fases da divisão celular e alterações cromossômicas encontradas.

\section{Análise estatística}

Os dados foram submetidos à análise da variância (ANOVA) e os valores dos índices mitóticos foram comparados pelo teste de Tukey com $5 \%$ de probabilidade de erro, com o auxílio do programa Sisvar 5.6.

\section{RESULTADOS E DISCUSSÃO}

Os resultados obtidos demonstram que os valores dos índices mitóticos variaram de $11,23 \%$ do controle negativo (água) a 4,85\% para o extrato aquoso na concentração de $15 \mathrm{~g} \mathrm{~L}^{-1}$ (Tabela 1).

TABELA 1. Número de células nas diferentes fases do ciclo celular de células meristemáticas radiculares de Allium Cepa L., tratados com diferentes concentrações de extratos de Handroanthus chrysotrichus (Mart. ex DC.) Mattos.

\begin{tabular}{|c|c|c|c|c|c|c|c|c|c|c|c|}
\hline \multirow{3}{*}{ Tratamento } & \multicolumn{10}{|c|}{ Ciclo Celular (Fases) } & \multirow{3}{*}{$\begin{array}{l}\text { Índice } \\
\text { Mitótico } \\
(\%)\end{array}$} \\
\hline & \multicolumn{2}{|c|}{ Intérfase } & \multicolumn{2}{|c|}{ Prófase } & \multicolumn{2}{|c|}{ Metáfase } & \multicolumn{2}{|c|}{ Anáfase } & \multicolumn{2}{|c|}{ Telófase } & \\
\hline & $\mathrm{RE}^{\star}$ & $\mathbf{I R}^{\star \star}$ & RE & IR & RE & IR & RE & IR & RE & IR & \\
\hline $\begin{array}{c}\text { Água } \\
\text { (controle } \\
\text { negativo) }\end{array}$ & 3551 & - & 158 & - & 104 & - & 86 & 2 & 99 & - & $11,23 \%^{a}$ \\
\hline $\begin{array}{l}\text { Glifosato } \\
\text { (controle } \\
\text { positivo) }\end{array}$ & 3922 & - & 26 & - & 22 & - & 14 & - & 16 & - & $1,95 \%{ }^{b}$ \\
\hline $\begin{array}{l}\text { Extrato } \\
5 \mathrm{~g} \mathrm{~L}^{-1}\end{array}$ & 3761 & - & 65 & - & 70 & - & 44 & - & 60 & - & $5,98 \%^{b}$ \\
\hline $\begin{array}{l}\text { Extrato } \\
10 \mathrm{~g} \mathrm{~L}^{-1}\end{array}$ & 3774 & - & 71 & - & 54 & - & 34 & - & 67 & - & $5,65 \%{ }^{a b}$ \\
\hline $\begin{array}{l}\text { Extrato } \\
15 \mathrm{~g} \mathrm{~L}^{-1}\end{array}$ & 3806 & - & 27 & - & 80 & - & 39 & - & 48 & - & $4,85 \%^{b}$ \\
\hline
\end{tabular}

Valores médios seguidos da mesma letra não diferem entre si pelo teste Tukey a $5 \%$ de probabilidade de erro.

$\mathrm{RE}^{*}=$ Regular; $\mathrm{IR}^{* *}=$ Irregular.

**Irregularidades: ponte na anáfase. 
Apenas um tratamento apresentou alterações cromossômicas, portanto os extratos aquosos de $H$. chrysotrichus não foram considerados genotóxicos. Quando analisados os índices mitóticos (Tabela 1) pode-se observar um decréscimo nos valores desses índices, sendo que, a água (controle negativo) apresentou o índice mitótico (IM) de 11,23\%, apresentando diferença significativa quando comparada aos outros tratamentos com IM de 5,98\% (extrato $5 \mathrm{~g} \mathrm{~L}^{-1}$ ), 5,65\% (extrato $10 \mathrm{~g} \mathrm{~L}^{-1}$ ) e $4,85 \%$ (extrato $15 \mathrm{gL}{ }^{1}$ ). Além disso, a redução do índice mitótico também foi significativa entre os dois controles, água destilada e glifosato, onde a água apresentou índice mitótico de $11,23 \%$ e o glifosato de 1,95\%. Quando comparados com o controle positivo (glifosato), com IM de 1,95\%, não houve diferença significativa em nenhum dos tratamentos.

Foi observado um decréscimo nos valores dos índices mitóticos para todos os tratamentos utilizados, sendo que na concentração de $15 \mathrm{gL}{ }^{1}$ a redução foi a maior de todos os tratamentos (Tabela 1). A inibição da divisão celular observada através dos valores dos índices mitóticos em $H$. chrysotrichus demonstrou que essa espécie possui capacidade antiproliferativa.

Outros resultados similares que também demonstraram atividade antiproliferativa de espécies vegetais, analisados pelo teste Allium cepa foram registrados por Hister et al. (2017), sendo possível observar que os índices mitóticos de extratos aquosos de Rusbus sp (amoreira-preta), foram reduzidos quando comparados com o controle negativo. Ao estudarem concentrações diferentes de Polygonum punctatum Elliott, Pastori et al. (2015), encontraram efeito antiproliferativo dos extratos, assim como Tedesco et al. (2015), que também encontraram efeito antiproliferativo em extratos de duas populações de Citrus sinensis (L.) Osbeck, porém, foi observado efeito genotóxico em ambas concentrações $\left(6 \mathrm{~g} \mathrm{~L}^{-1}\right.$ e $\left.24 \mathrm{~g} \mathrm{~L}^{-1}\right)$, com maior número de aberrações cromossômicas na concentração de maior dose.

Quando avaliaram o extrato hidroalcoólico de cascas de Hymenaea stigonocarpa em células meristemáticas de Allium cepa L., Silva et al. (2014), também encontraram efeito antiproliferativo e não genotóxico nas três concentrações analisadas. Resultado semelhante foi observado por Dornelles et al. (2017) para a espécie Richardia brasiliensis Gomes, que apresentou, em diferentes concentrações de extratos e frações, efeito antiproliferativo e genotóxico. Sendo que, os tratamentos que continham a concentração mais alta $\left(500 \mu \mathrm{mL}^{-1}\right)$ foram os que apresentaram maior diferença estatística quando comparados ao controle negativo.

\section{CONCLUSÃO}

Por meio da análise dos resultados obtidos através das diferentes concentrações de extratos das cascas de Handroanthus chrysotrichus pelo sistema teste de Allium cepa L., foi possível verificar a presença de atividade antiproliferativa e não genotóxica da espécie, indicando um potencial para inibição do ciclo celular.

\section{AGRADECIMENTOS}

Agradecemos a Prof ${ }^{\underline{a}}$ Dra. Liliana Essi, pela identificação do Handroanthus chrysotrichus (Mart. ex DC.) Mattos. 


\section{REFERÊNCIAS}

BAGATINI, M. D; SILVA, A. C. F; TEDESCO, S. B. Uso do sistema teste de Allium cepa como bioindicador de genotoxicidade de infusões de plantas medicinais. Revista Brasileira de Farmacognosia, [s.I] v. 17, n.3, p.444-447, 2007. FapUNIFESP (SciELO). Disponível em: <http://dx.doi.org/10.1590/S0102695X2007000300019>. doi: 10.1590/S0102-695X2007000300019

BOLSON, M.; HEFLER, S. R.; CHAVES, E. I. D.; JUNIOR, A. G.; JUNIOR, L. C. E. Ethno-medicinal study of plants used for treatment of human ailments, with residents of the surrounding region of forest fragments of Paraná, Brazil. Journal of Ethnopharmacology, [s.l] v. 161, p.1-10, february. 2015. Disponível em: <https://doi.org/10.1016/j.jep.2014.11.045>. doi: 10.1016/j.jep.2014.11.045

DE CANDOLLE, A. P.; Revue sommaire de la familledês Bignoniacées. Genève: Bibliotheque Universelle de Genève. 20 p. 1838. Disponível em: <https://babel.hathitrust.org/cgi/pt?id=hvd.32044107252306;view=1up;seq=3> Acesso em: 02 fev. 2019.

DORNELLES, R. C.; LEAL, G. C.; DECIAN, A. C. S.; SANTOS, D. D.; RADISKE, G. A.; MANFRON, M. P.; TEDESCO, S. B. Iheringia, v.72, n.3, p.424-431. dez 2017. Disponível em:<https://isb.emnuvens.com.br/iheringia/article/viewFile/659/377>. Acesso em: 02 abr. 2019 doi: 10.21826/2446-8231201772313.

FERREIRA, B. S.; NEIVA, J.; NUNES, G.; BARATA, J. Hepatite Tóxica Induzida por Produtos Fitoterapêuticos: Natural Não é Sinônimo de Seguro. Gazeta Médica. [s.I] v.3, n.3, p.128-131. jul/set 2016. Disponível em: $<$ http://www.gazetamedica.com/index.php/gazeta/article/view/106/42>. Acesso em: 20 mar. 2019.

GUERRA, M.; SOUZA, M. J. Como observar cromossomos: um guia de técnicas em citogenética vegetal, animal e humana. Ribeirão Preto: FUNPEC, 2002, 131p. Disponível em: <http://www.ensp.fiocruz.br/portal-ensp/_uploads/documentospessoais/documento-pessoal_52172.pdf>. Acesso em 02 fev. 2019.

GROSE, S. O.; OLMSTEAD, R. G. Taxonomic revisions in the polyphyletic genus Tabebuias.I. (Bignoniaceae). Systematic Botany, [s.I] v. 32, n. 3, p.660-670, jul 2007. Disponível em: <https://doi.org/10.1600/036364407782250652>. doi: $10.1600 / 036364407782250652$

HERRERO, O; PÉREZ MARTíN, J. M; FERNÁNDEZ FREIRE, P.; CARVAJAL LÓPEZ, L.; PEROPADRE, A., et al. Toxicological evaluation of three contaminants of emerging concern by use of the Allium cepa test. Mutation Research. [s.I]v. 743, n. 1-2, p.20-14, 2012. Disponível em: $<$ https://doi.org/10.1016/j.mrgentox.2011.12.028>. doi: 10.1016/j.mrgentox.2011.12.028

HISTER, C. A. L.; PASQUALLI, M.; TRAPP, K. C.; STEFANELLO, R.; BOLIGON, A. A., et al. Atividade antiproliferativa e determinação dos compostos fenólicos de extratos aquosos de amoreira-preta (Rubus sp.) pelo sistema teste in vivo de Allium cepa L. Revista Brasileira de Biociências, Porto Alegre, v. 15, n. 1, 2017. 
Disponível em: http://www.ufrgs.br/seerbio/ojs/index.php/rbb/article/view/3811. Acesso em: 20 mar. 2019.

LEAL, L. R.; TELLIS, C. J. Farmacovigilância de plantas medicinais e fitoterápicos no Brasil: uma breve revisão. Revista Fitos, Rio de Janeiro, v.9, n. 4, p.253-303, out/dez 2015. Disponível em: <http://dx.doi.org/10.5935/2446-4775.20150020>. doi: $10.5935 / 2446-4775.20150020$

LEITE, D. M.; DAMASIO, J. F.; MELLO, V. S. de; FERNANDES, L.; KARSBURG, I. V. Determinação do número cromossômico de Handroanthus chrysotrichus (Bignoniaceae). Revista de Ciências Agroambientais. [s.I] v.15, n.1, 2017. Universidade do Estado de Mato Grosso. Disponível em: <https://periodicos.unemat.br/index.php/rcaa/article/view/2201/1792>. Acesso em: 20 mar. 2019.

LUNELLI, N. P.; RAMOS, M. A.; OLIVEIRA JUNIOR, C. J. F. Do gender and age influence agroforestry farmers' knowledge of tree species uses in an area of the Atlantic Forest, Brazil?. Acta Botanica Brasilica, Belo Horizonte, v. 30, n. 4, p.667682, oct/dec. $2016 . \quad$ FapUNIFESP(SciELO) em:<http://dx.doi.org/10.1590/0102-33062016abb0226>.doi:

Disponível $33062016 a b b 0226$

MATTOS, J.R.; Handroanthus, um novo gênero para os "ipês" do Brasil. Loefgrenia, n. 50, p. 1-4, 1970.

MELO, A. F. M. de; SILVA, J. R. G. da; AMORIM, M.E. S.; CORDEIRO, B. A.; CORDEIRO, R. P. Comunidade e uso racional de plantas medicinais. Extramuros, Petrolina-PE, v.5, n.1, p.80-88, 2017. Disponível em: <http://www.periodicos2.univasf.edu.br/index.php/extramuros/article/view/926/733>. Acesso em: 20 mar. 2019.

NÓBREGA, A. L.; UGULINO, P. T. D.; CAJÁ, D. F.; DANTAS, A. E. F. A importância da orientação dos profissionais das equipes de saúde da família a cerca do uso da fitoterapia. Revista Brasileira de Educação e Saúde, Pombal, PB, v.7, n.1, p.4348, 2017. Disponível em: <http://dx.doi.org/10.18378/rebes.v7i1.3768>. doi: 10.18378/rebes.v7i1.3768

NOLDIN, V.F.; MONACHE, F. D.; YUNES, R. A. Composição química e atividade biológica de Cynara scolymus L. cultivada no Brasil. Química Nova, São Paulo, v.26, n.3, p.331-334, 2003. FapUNIFESP (SciELO). Disponível em: <http://dx.doi.org/10.1590/S0100-40422003000300008>. doi: 10.1590/S010040422003000300008

PASTORI, T., KUHN, A.W., TEDESCO, M., HOFFMANN, C.E., NEVES, L.A.S., et al. Ação genotóxica e antiproliferativa de Polygonum punctatum Elliott (Polygonaceae) sobre 0 ciclo celular de Allium cepa L. Revista Brasileira de Plantas Medicinais, v.17, n.2, p.186-194. 2015. FapUNIFESP (SciELO). Disponível em:<http://dx.doi.org/10.1590/1983-084X/13_023>.doi: 10.1590/1983-084X/13_023 
PEREIRA, M. O.; NAVROSKI, M. C.; REINIGER, L. R. S. Multiplicação in vitro de Ipê-Amarelo (Handroanthus chrysotrichus). Nativa: Pesquisa Agrárias e Ambientais, [s.l] v.03, n. 01, p.59-63, jan/mar. 2015. Universidade Federal de Mato Grosso. Disponível em: <http://dx.doi.org/10.14583/2318-7670.v03n01a10>. doi: 10.14583/2318-7670.v03n01a10

PLANTAS medicinais. Handroanthus chrysotrichus (Mart. ex D.C.) Mattos. Ipêamarelo. Compêndio Online Gerson Luiz Lopes Laboratório de Manejo Florestal. Disponível em: <https://sites.unicentro.br/wp/manejoflorestal/111932/>. Acesso em: 20 mar. 2019.

SANTOS, S. R.; A atual classificação do antigo gênero Tabebuia (Bignoniaceae) sob o ponto de vista da anatomia da madeira. BALDUINIA, [s.I] n. 58, p.10-24, 15-VII2017. Universidade Federal de Santa Maria. Disponível em: <http://dx.doi.org/10.5902/2358198028146>. doi: 10.5902/2358198028146

SILVA, L. M. da; PERON, A. P.; CARVALHO, F. R. S.; MARTINS, L.; CALOU, I. F. B. et al. Efeito antiproliferativo do extrato hidroalcoólico de Hymenaea stigonocarpa Mart. ex Hayne (Fabaceae, Caesalpinioideae) sobre as células meristemáticas de raízes de Allium cepa L. Biotemas, Florianópolis, v. 28, n. 1, p. 45-49, nov. 2014. Disponível em: <https://doi.org/10.5007/2175-7925.2015v28n1p45>. doi: 10.5007/2175-7925.2015v28n1p45

TEDESCO, M.; KUHN, A. W.; BOLIGON, A. A., LAUGHINGHOUSE IV, D. H., ATHAYDE, M.L., et al. Chromatographic analysis, antiproliferative effect and genotoxicity of aqueous extracts of Citrus sinensis (L.) OSBECK on the Allium cepa L. test system. Bioscience Journal, Uberlândia, v. 31, n. 4, p.1213-1221, july/aug. 2015. Disponível em: <http://dx.doi.org/10.14393/BJ-v31n4a2015-23245>. doi:10.14393/BJ-v31n4a2015-23245

TEDESCO, S. B.; LAUGHINGHOUSE IV, D. H. Bioindicator of Genotoxicity: The Allium cepa Test. Environmental Contamination, [s.I.], p.137-156, 29 fev. 2012. InTech. Disponível em: <http://dx.doi.org/10.5772/31371>. doi: 10.5772/31371

VEIGA JUNIOR, V. F.; PINTO, A. C.; MACIEL, M. A. M. Plantas Medicinais: cura segura? Química Nova, São Paulo, v. 28, n. 3, p. 519-528, 2005. FapUNIFESP (SciELO). Disponível em: <http://dx.doi.org/10.1590/S0100-40422005000300026>. doi: 10.1590/S0100-40422005000300026 